\title{
DIREITO ECONÔMICO DO SETOR PESQUEIRO: REESTRUTURAÇÃO PRODUTIVA BASEADA EM SUBSÍDIOS À INDÚSTRIA PESQUEIRA NACIONAL
}

\section{ECONOMIC LAW OF FISHERIES: PRODUCTIVE RESTRUCTURING BASED ON SUBSIDIES TO THE FISHERIES NATIONAL INDUSTRY}

Vera Lucia da Silva ${ }^{1}$

\section{RESUMO}

Este artigo tem por objetivo analisar a restruturação produtiva do setor pesqueiro brasileiro, cuja razão foi a política de subsídios prevista no Código de Pesca de 1967. Para tanto, utilizou-se de categorias típicas do direito econômico. Assume-se, desde o início, a subdivisão entre normas regulamentares e institucionais, bem como a instrumentalidade do direito econômico em relação ao planejamento nacional. Posteriormente, aplica-se tais ideias à legislação do setor pesqueiro. A seguir, são apresentadas as modalidades de fomento previstas no Código de Pesca de 1967. Finalmente, relaciona-se tais medidas com a restrutruração produtiva do setor pesqueiro, do modelo artesanal para industrial.

Palavras-chave: Direito econômico, Setor pesqueiro, Processo de reestruturação produtiva

\begin{abstract}
This paper aims to analyze the productive restructuring process of Brazilian fisheries based on the subsidy policies, established in Fisheries Code of 1967. For this purpose, we used typical categories of economic law. We assumed, from the beginning, the differences between regulatory and institutional norms, and the instrumentality rule of economic law in relation to national planning. Following, we applied these ideas to study the legislation for fishing sector. Then, we presented the funding arrangements established in the Fisheries Code of 1967. Finally, we related such measures to the productive restructuring process on fisheries, from artisanal to industrial model.
\end{abstract}

Keywords: Economic law, Fisheries, Productive restructuring process

1

Doutora em Direito pela Universidade Federal de Santa Catarina, com período de estágio doutoral na

Vanderbilt University. Assistente Jurídica na PGE/SC. Advogada. E-mail: indexlaw.ojs@hotmail.com 


\section{INTRODUÇÃO}

Tomando a subdivisão das normas de Direito Econômico em duas categorias - normas regulamentares e institucionais - pretende-se analisar as normas que estabeleceram subsídios à produção pesqueira nacional previstas no Código de Pesca de 1967. Ambas modalidades normativas de direito econômico foram utilizadas no estímulo à pesca nacional, dado o modelo de gestão por subsídios adotado no Brasil.

O Código de Pesca de 1967 foi o instrumento normativo que definiu as empresas pesqueiras como indústrias de base, destinando-lhes estímulo econômico via empréstimos a juros módicos e isenção tributária. Tais formas de fomento devem ser compreendidas sem perder de vista o contexto do planejamento econômico nacional, dada a vinculação dos subsídios à pesca com a política econômica vigente. Aceita-se, portanto, desde o início, a premissa que define o Direito Econômico do Setor Pesqueiro como o reflexo dos propósitos de planejamento econômico nacional na gestão da atividade pesqueira.

A forma de subsídios adotada, aliada à análise do contexto de planejamento econômico nacional, permite perceber o esforço governamental para reestruturação produtiva do setor pesqueiro. Se até o Código de Pesca de 1967, as medidas de fomento eram fragmentárias e diversificadas, a partir deste instrumento legal passaram a ser unificadas e direcionadas ao subsetor industrial da pesca. Foi nesse momento que ganhou sentido a subdivisão entre pesca artesanal e pesca industrial, com vistas ao desenvolvimento desta última modalidade. Tratou-se, por fim, de estimular a reestruturação produtiva de um setor essencialmente artesanal, com o objetivo de estabelecer patamares industriais de produção, indiferentemente ao possível esgotamento dos estoques pesqueiros ser consequência dessa reestruturação.

Apesar dos estudos já produzidos sobre a organização da pesca no Brasil, o campo de análise da legislação econômica pesqueira permaneceu esquecido. Os modelos de gestão dos recursos pesqueiros adotados no Brasil não foram suficientemente questionados nas poucas páginas dedicadas à pesquisa sobre legislação pesqueira nacional. Portanto, pretende-se propor a investigação desse campo normativo, a fim de compreender o processo de reestruturação produtiva do setor pesqueiro. A partir dessa análise, torna-se possível discutir a falência da pesca artesanal e a depleção dos estoques pesqueiros em águas nacionais. 


\section{DIREITO ECONÔMICO: ENTRE NORMAS REGULAMENTARES E INSTITUCIONAIS}

Os papéis de regulamentar ou atuar diretamente na economia são, a todo tempo, incorporados pelo Estado (SILVA, 1974, p. 32). É mesmo elementar a qualquer noção de Estado, seja este considerado como associação ou ente ${ }^{1}$, sua atribuição de regular as relações humanas. Ainda que seja admitida uma perspectiva cética em relação ao Estado, sob a qual a este elemento da convivência humana não é essencial a realização de finalidades (portanto, em negação a mais comum definição de origem aristotélica ${ }^{2}$ ), é fundamental a dimensão regulamentar à sua definição mínima.

Por isso, em todo conceito de Estado, é possível reconhecer na sua base alguma espécie de regulamentação das atividades humanas; econômicas, no mais das vezes (VENANCIO FILHO, 1968, p. 63). Compreenda-se, aqui, por atividade econômica as mais diversas formas de interação entre sujeitos, com o escopo de gerar riqueza. Se o Estado se define pelo poder de regulamentar inclusive a economia, a submissão desta às decisões políticas é uma das consequências. Mesmo que seja considerado o modelo teórico definido como Estado Liberal (aqui, oposto ao Absoluto), caracterizado fundamentalmente pela maior liberdade de agir aos cidadãos, tem-se necessariamente a regulação como instrumento à garantia das liberdades.

Essa perspectiva geral e até mesmo funcional do Estado é tributária de certo racionalismo institucional. É o horizonte sob o qual o Estado pode ser científica e universalmente definido, por meio da função que desempenha. Por sua vez, a identidade do Estado com regulamentação implica o racionalismo das instituições, com previsibilidade do

\footnotetext{
${ }^{1}$ A diferença entre considerar o Estado como associação ou ente está, fundamentalmente, na origem das decisões. Enquanto ente, cogita-se a existência de uma vontade estatal própria, diversa e superior às vontades individuais. Por outro lado, o Estado como associação tem por centro decisório processos de escolhas variados, mas referente à deliberação ou comando de líderes - nunca se supõe uma vontade própria. Nesse ponto, Modesto Carvalhosa foi bastante esclarecedor, assumindo o pressuposto do Estado como ente: "No esforço de configurar essas realidades, deve-se evitar a tendência de encarar o Poder Público como um mero instrumento utilizável pelas entidade econômicas privadas, na medida em que o momento atual demonstra um claro contraste de interesses entre ambos. Por outro lado, não se deve tomar por base as FUNÇÕES do Estado, apenas analisando a maior ou menor dimensão dessas funções, já que tal critério teria por mérito ressaltar, apenas, o caráter estático e funcional do Poder Público, descurando-se do aspecto político, ou seja, da vontade do Estado, num determinado tempo e espaço". (CARVALHOSA,1973, p. 46).

${ }^{2}$ Aqui, tradicionalmente, utiliza-se a referência à subdivisão metafísica aristotélica. Esta subdivisão sugere a definição dos seres pelas suas quatro causas - a partir delas é possível agrupar os seres em categorias. Dentre as quatro causas, está a finalidade: o fim para que o objeto existe é uma causa que agrupa diversos objetos. (ARISTÓTELES, , p.37-80). Portanto, as normas jurídicas também podem ser categorizadas, a fim de gerar um conhecimento comum a um grupo de normas. Uma aplicação prática desse ditame da racionalidade permite agrupar normas estatais com uma finalidade similar. No caso do presente trabalho, o intuito é agrupar as normas jurídicas que, além de terem a mesma origem e forma, ainda são destinadas à finalidade de definir os limites da atuação estatal na economia e, mais especificamente, no setor produtivo pesqueiro nacional.
} 
exercício do poder. Portanto, a racionalização institucional pode ser definida como o processo de conferir características de previsibilidade e segurança nos procedimentos publicamente $\operatorname{adotados}^{3}$.

Reunidos, por um lado, Estado (e seu poder regulamentar) e racionalização, e, por outro, economia, o resultado é a identificação de um agregado de normas estatais que preveem as formas pelas quais se organiza a atividade econômica. Em verdade, essa não é uma dimensão recém descoberta do Estado; mas a autonomia na análise das normas regulamentares sobre o ramo econômico é derivada da especialização e setorização funcional das normas jurídicas.

Nesse sentido, pode-se compreender o debate sobre a natureza do Direito Econômico. Enquanto alguns autores o definem como método de análise do direito, outros o enquadram como novo ramo da ciência jurídica. A consequência de fazer do Direito Econômico um novo campo autônomo é a necessidade de delimitar seu objeto - o que é também um desafio. Por outro lado, a consideração do Direito Econômico como metodologia indica a necessidade de integrá-lo na análise das disciplinas tradicionais da ciência jurídica: desafio de igual dimensão que considerá-lo um ramo autônomo. Portanto, em termos de economia teórica, qualquer dos enquadramentos do Direito Econômico é custoso e instável.

Assim, o Direito Econômico não seria considerado uma disciplina dogmática tradicional autônoma, que trabalha a exegese de determinado campo de normas jurídicas. Antes, o Direito Econômico deve ser considerado um método hermenêutico a integrar as disciplinas tradicionais. Esse argumento encontrou respaldo inclusive no pensamento de Eros Roberto Grau, que considerou o Direito Econômico, para além de um ramo autônomo da ciência jurídica, um novo método de análise caracterizado pelo sincretismo metodológico, dada a abertura que proporciona à hermenêutica de todo o ordenamento (GRAU, 2007, p. 153). Considerar o Direito Econômico como um método é destacar, na ordem jurídica, as finalidades sociais da regulação econômica estatal e imprimi-la a todas as disciplinas e ramos da ciência jurídica.

Ademais, considera-se que a nova disciplina tem por objeto um conjunto de normas bastante definido, das quais se pode considerar como principal característica o estabelecimento de medidas de política econômica. Esse é o caso de Fábio Comparato e de

\footnotetext{
3 "São clássicas as considerações de Weber: as exigências de calculabilidade e confiança no funcionamento da ordem jurídica e na administração constituem uma exigência vital do capitalismo racional; o capitalismo industrial depende da possibilidade de previsões seguras - deve poder contar com estabilidade, segurança e
} 
objetividade no funcionamento da ordem jurídica e o caráter racional e, em princípio, previsível das leis e da administração." (GRAU, 2007, p. 32).

Modesto Carvalhosa, este mudando o posicionamento teórico já na sua segunda obra sobre

Direito Econômico.

\begin{abstract}
Imprescindível, no entanto, verificar se o Direito Econômico teria um caráter originário. Cabe ver se, no ordenamento, existe um grupo, ou antes, um particular sistema de normas, no qual se note identificação de objeto ou homogeneidade estrutural. (... ) Essas regras positivas formam o arcabouço da Ordem Econômica, em razão da qual a atividade produtiva passa a mover-se sensivelmente pelas coordenadas que lhe são impostas ou sugeridas pela ordem jurídica e não somente pelos termos do mercado. Da sistematização e síntese dessas normas é que se poderá traçar os limites do Direito Econômico, identificando os seus sujeitos, objetos e fontes (COMPARATO, 1965, p. 14).
\end{abstract}

Seguindo essa mesma orientação, Eros Grau também apresentou uma proposta conciliatória entre as duas concepções sobre o Direito Econômico, considerando-o tanto como método quanto novo ramo da ciência jurídica. A consequência é retornar às duas dificuldades anteriormente expostas: definição do método e do objeto.

O desafio de definir o objeto do Direito Econômico parece resolvido com a formulação de Washington Peluso Albino de Souza: normas que regulamentam medidas de política econômica. Assim, o Direito Econômico seria a disciplina que reúne normas caracterizadas por, concomitantemente, prever o estabelecimento do mercado e harmonizar interesses individuais e coletivos, orientadas pela economicidade (limites racionais para concretização de objetivos individuais e sociais) (SOUZA, 1980, p. 06). Para o autor, o Direito Econômico tem como finalidade a adequação da economia à ordem jurídica vigente, coibindo os abusos no exercício da atividade econômica, bem como disciplinando a economia a fim de promover o desenvolvimento (CARVALHOSA, 1971, p.176). Assim, tal como outros ramos autônomos do Direito, é possível discernir objeto e características próprias do Direito Econômico.

Dada a finalidade de regulamentar a atividade econômica, adequando-a aos fins estatais, é possível identificar um grupo diferenciado de normas que compõem o Direto Econômico. Apesar dessas normas não comporem um agregado único codificado (molde típico à tradição legal brasileira) é distinguível, sem grandes esforços, um conjunto normativo submetido a princípios comuns, dado o objeto (e o objetivo) dessas normas. Nesse sentido, o Direito Econômico é caracterizado por seu caráter fragmentário, o que, no entanto, não o descaracteriza como um ramo da ciência jurídica. 
Partindo dessas considerações sobre o Direito Econômico, tido, concomitantemente, como método hermenêutico funcionalista e como ramo da ciência jurídica orientado pela consecução de políticas econômicas; ou seja, da conciliação entre as duas perspectivas inicialmente opostas, é possível deduzir o caráter racionalizante do Direito Econômico. Isso porque essas normas econômicas, ou a interpretação de normas sob o método funcional do Direito Econômico, são orientadas para a realização de finalidades.

Assim, o Direito Econômico, como elemento racionalizante, é a base para a dita Ordem Econômica. Nesse ponto, o Direito garante a racionalidade técnica dos preceitos políticos de justiça na esfera econômica. Isso significa que as normas jurídicas econômicas conferem a previsibilidade necessária para a organização do mercado, orientando as condutas das partes, bem como a participação do Estado na exploração das atividades.

As regras jurídicas sobre a economia devem possibilitar a conformação dos mercados, mas não determiná-los; o conteúdo das trocas e das negociações é estabelecido pelas partes envolvidas nas relações comerciais. Entretanto, essa liberdade só é viável por meio da regulação do Direito Econômico ${ }^{4}$. Segundo Neumann, "a tarefa primordial do Estado é criar um Estado legal que garanta a execução dos contratos, pois uma parte indispensável para o sucesso empresarial é saber com certo grau de certeza que os contratos serão respeitados"(NEUMANN, 1969, p.50).

Por isso, a classificação das normas de Direito Econômico sugerida por Venâncio Filho, proposta originalmente por Bernard Chenot, foi adotada no âmbito deste trabalho, por sua economicidade. Consideram os autores que o Direito Econômico está comprometido com a sistematização de normas jurídicas econômicas que, mesmo esparsas, apresentam igual finalidade: a regulamentação da intervenção estatal no campo econômico. Tais normas podem ser classificadas tendo em vista a forma de atuação estatal prevista, segundo duas categorias: Direito Regulamentar e Direito Institucional (VENÂNCIO FILHO, 1968, p.65). O Direito Econômico Regulamentar dedica-se às normas em que o papel do Estado é unicamente normativo, regrando as atividades econômicas e organizando a atuação dos setores. Já o Direito Econômico Institucional é destinado ao estudo do conjunto de normas que orientam a atuação direta do Estado como agente econômico.

Assim, a subdivisão do Direito Econômico em dois grandes ramos utilizada por Venâncio Filho é inspirada pelos dois papéis possíveis ao Estado (agente econômico ou agente regulador) e não na natureza das normas jurídicas econômicas. O caráter das normas jurídicas econômicas é conferido pelo papel assumido pelo Estado, e não pelo conteúdo de acesso ou de exercício, conforme a classificação oferecida por Carvalhosa. 
4 “O sentido integrativo da proposta estatal no domínio econômico importa, assim, num requisito indispensável de ordenação em que resulte manifesta a certeza das relações jurídicas como elemento fundamenta para o efetivo desenvolvimento da sociedade e aí o respeito aos direitos fundamentais de liberdade assegurados pela Carta Magna”. (CARVALHOSA, 1971, p. 13).

Portanto, o Direito Regulamentar se define por normas que orientam a exploração dos setores da economia; já o Direito Econômico Institucional reúne normas que preveem a ação direta do Estado nas atividades econômicas. Na primeira modalidade, o Estado promove a organização jurídica de um setor econômico a ser explorado fundamentalmente pela iniciativa privada. Na segunda, os investimentos privados, quando existentes, são complementares: a atividade conta com organização legal e exploração direta estatal, por via de entes da Administração Pública Indireta ${ }^{5}$.

\title{
3 DOS SUBSÍDIOS SETORIAIS COMO NORMAS DE FOMENTO NO CONTEXTO DE PLANEJAMENTO ECONÔMICO NACIONAL
}

Considerando que muitos dos setores econômicos nacionais foram estruturados com base em investimentos públicos, face à alegada carência de recursos do tardio empresariado nacional, surgem os entes da Administração Indireta, atuantes conforme o Direito Institucional. Esses entes são submetidos à lógica do Direito Público, embora exerçam atividades e contratos típicos da iniciativa privada. São, na verdade, entes suplementares, e mesmo necessários, ao estabelecimento do mercado interno nacional.

\begin{abstract}
Inicialmente era o próprio Estado que desenvolvia os serviços públicos necessários ao desenvolvimento da sociedade. Posteriormente, verificou-se que estas atividades poderiam ser delegadas a empresas nas quais o Estado agiria como se privado fosse, apenas como acionista, exclusivo ou majoritário. Surgem daí as empresas estatais (sociedades de economia mista e empresas públicas). Em um momento seguinte, mais recentemente, fruto de um processo de desestatização, os capitais públicos foram alienados e passaram a existir sociedades criadas com capitais privados, sob a forma de entes privados, para o desenvolvimento de atividades próprias do Estado, ou seja, a prestação de serviços públicos. Neste caso, o art. 175 da Constituição Federal menciona 'incumbir ao poder público, diretamente ou sob regime de concessão ou permissão, sempre através de licitação, a prestação de serviços públicos. [...] De qualquer forma, o controle legal se impõe, seja em razão do interesse público envolvido, seja em razão das verbas públicas utilizadas (CAL, 2013, p.08).
\end{abstract}

Nesse contexto, o Direito Institucional foi (e continua sendo) vital para ordenar tanto o desenvolvimento como a consolidação de atividades que implicassem vultosos investimentos ou grandes riscos. A criação das entidades autárquicas e das empresas públicas foi o modelo adotado, a partir da década de 1940, para a consolidação de mercados tão 
5 “Há mesmo uma parte do Direito Econômico, tal como o mesmo é visto pelos autores citados (Venâncio filho e Bernard Chenot), que recebe a denominação de Direito Institucional Econômico, dedicada especialmente ao estudo da intervenção do Estado através dos órgãos da administração indireta, de tão grande importância para a vida jurídica, econômica, administrativa e política do Estado”. (SILVA, 1974, p. 33).

onerosos quanto essenciais ao desenvolvimento nacional, como, por exemplo, a siderurgia ${ }^{6}$.

Pela criação das entidades autárquicas e empresas públicas, foi possível garantir elementos para a transformação econômica necessária ao país, especialmente para subsidiar a continuidade e intensificação do processo de substituição de importações, iniciado na década de 1930.

Além de explorar mercados ainda não consolidados e carentes de investimentos privados $^{7}$, a atuação institucional do Estado na economia brasileira foi adotada como um modelo de desenvolvimento também para setores já tradicionais. Dessa forma, a partir da década de 1930, foram criadas autarquias econômicas para defesa de produtos agrícolas e da indústria extrativa (VENANCIO FILHO, 1968, p. 62).

Paralelamente a esse processo de consolidação da atividade econômica estatal via Direito Institucional a partir de 1930, a regulamentação dos setores da economia foi intensificada. Parece elementar afirmar que, antes dos anos de 1960, e, portanto, da fixação do modelo de planejamento econômico nacional, já havia intensa participação estatal na regulamentação do mercado brasileiro. A sequência institucional do período conhecido como Era Vargas estabeleceu consenso sobre o papel essencial do Estado no desenvolvimento econômico nacional ${ }^{8}$. E, a partir de então, foi atribuído ao Direito Regulamentar um caráter finalístico de organizar os mercados e estimular as atividades produtivas.

É verdade que ações estatais para a defesa dos produtores de café e de outros gêneros de exportação já eram comuns no Brasil desde o período do Segundo Império ${ }^{9}$. Já na República, casos de intervenção como os do Convênio de Taubaté não eram isolados ${ }^{10}$. Mas o

\footnotetext{
${ }^{6} \mathrm{O}$ desenvolvimento da siderurgia no Brasil era condição necessária ao desenvolvimento industrial, a fim de suprir a demanda de aço, matéria-prima essencial à indústria. A ausência de investimentos suficientes para formar a indústria siderúrgica no Brasil, aliada ao desenvolvimentismo nacionalista de Getúlio Vargas, foi o impulso para a criação, em 1941, da Companhia Siderúrgica Nacional (CSN). Sua criação foi polêmica, inicialmente apoiada pelos Estados Unidos da América durante os esforços comuns de guerra. Dado o fim do conflito, os Estados Unidos recuaram no estímulo à criação da Siderurgia no Brasil. Pelas dificuldades de financiamento, a CSN entrou em operação somente em 1946 e supriu grande parte das demandas nacionais de aço no início do período de industrialização da produção nacional. Foi privatizada em 2006, diversificando investimentos em setores da construção civil e mineração. (ABREU, 1990, p.98-99).

7 "O papel do Estado no Brasil ao longo do período (republicano) caracterizou-se por sua natureza essencialmente complementar às iniciativas do setor privado. Não se tratou de ocupar segmentos estratégicos em substituição à iniciativa privada, mas, fundamentalmente, de investir em áreas nas quais não houve interesse privado nacional ou estrangeiro". (ABREU, 1990, p. 09).

${ }^{8}$ Especialmente quando do intervencionismo autoritário, característico do período conhecido como Estado Novo (1937- 1945). Nesse momento, são formados os primeiros Conselhos Técnicos, os que produziam relatórios especializados para orientar as decisões estatais. (VIANNA, 1947, p. 205).
} 
${ }_{1}^{9}$ Dentre esses casos, deve-se mencionar a Reforma Alves Branco, de 1944. (VENANCIO FILHO, 1968, p. 25).

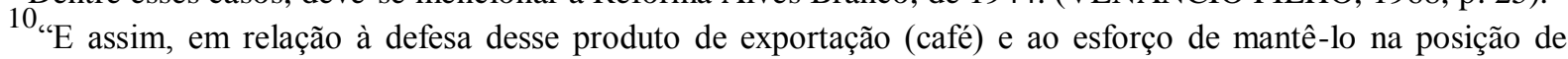
destaque nos mercados internacionais, que se processam as medidas iniciais de intervenção mais ativa do Estado no domínio econômico, que a partir daí, cada vez mais se acentuam (...). É digno de relevo que essa intervenção se processa inicialmente por iniciativa dos principais Estados produtores: São Paulo, Minas Gerais e Rio de

fato é que essas intervenções eram momentâneas, setoriais e diversificadas, sujeitas aos intensos lobbies políticos; era necessário coordenar os esforços públicos para o desenvolvimento econômico brasileiro.

Aponta-se essa mesma insuficiência dos investimentos do empresariado nacional como razão da intervenção estatal brasileira na economia, seja através do Direito Regulamentar ou pelo Direito Institucional. Conjuntamente, indica-se a dificuldade de estabelecer um mercado consumidor interno como causa para os níveis insuficientes de investimento privado. Sob tais determinantes, o Brasil, ainda em 1960, era um país eminentemente agrário, dependente das exportações de produtos primários e carente de produtos industriais (PRADO JÚNIOR, 1967, p.268), na sua maior parte importados. Com o fenômeno conhecido como deterioração dos termos de troca (perda do valor de troca dos produtos primários em face aos industriais), era cada vez mais difícil manter ou mesmo conceber o desenvolvimento econômico brasileiro ${ }^{11}$.

Ora, a concessão de incentivos estatais de qualquer natureza não pode ser considerada condição de exercício de atividade econômica, no sentido estrito. É, antes, uma faculdade do investidor privado em acessar (ou não) as modalidades de fomento disponibilizadas pelo Estado. Dessa forma, o tratamento dessas normas de fomento deve ser alinhado às normas dispositivas, e não cogentes. Por isso, o Direito Regulamentar é, inicialmente, um ramo inadequado para o tratamento dessas normas de fomento.

Quando são consideradas as normas de fomento, entretanto, a hermenêutica destacase da ponderação típica do Direito Regulamentar. Isso porque, embora essas normas de fomento tenham como destinatários a iniciativa privada, seu processo hermenêutico deve exclusivamente ser orientado pelo interesse público. Esse fato parece elementar, dado que as normas de fomento acarretam, necessariamente, investimentos e gastos públicos. Pelos limites hermenêuticos, nem o Direito Institucional e nem o Direito Regulamentar parecem ramos adequados ao tratamento das normas de fomento.

A eficácia das medidas previstas nos planos econômicos depende de previsão legal específica. Assim, como parte do instrumental do planejamento, surgem as normas de fomento à atividade econômica. São essas normas as que preveem incentivos à iniciativa 
Janeiro, que em 1906 celebraram o Convênio de Taubaté, regulando elementos de intervenção, passando a União Federal posteriormente a intervir diretamente na matéria”. (VENANCIO FILHO, 1968, p. 28).

${ }^{11}$ Para Octávio Rodriguez, no caso brasileiro a CEPAL identificou as "[...] três tendências consideradas inerentes à industrialização periférica: o desemprego estrutural, o desequilíbrio externo e a deterioração dos termos de intercâmbio". (RODRIGUEZ, 1981, p.20). privada. Por isso, além de estabelecer as modalidades e as condições para acesso aos benefícios, são normas que elegem os destinatários e suas características.

\begin{abstract}
Consequência natural do planejamento econômico dentro de um regime que privilegia a livre iniciativa é o fomento, incluído por Diogo de Figueiredo Moreira Neto como uma das funções da Administração - ao lado do poder de polícia, da prestação de serviços públicos e do ordenamento econômico e social -, através da qual o Estado atual procura, por todos os meios a seu alcance, pôr à disposição do maior número possível de indivíduos os instrumentos do desenvolvimento econômico e do progresso sociocultural, adotando medidas capazes de incentivar a iniciativa privada de interesse coletivo nesses campos. (SOUTO, 2000, p. 53)
\end{abstract}

Por serem normas que concretizam o planejamento e concedem o fomento à iniciativa privada, são completamente facultativas quanto à adesão por parte da iniciativa privada. Porém, uma vez aceitas as condições do fomento, a relação passa a ser de obrigatoriedade, regrada pelo Direito Público.

Dentre as espécies de fomento possíveis, há benefícios e incentivos tributários, garantias públicas para captação de investimentos, subsídios (donativos a fundo perdido), empréstimo em condições diferenciadas, assistência técnica estatal e protecionismo. Todas essas modalidades, em conjunto ou isoladamente, são maneiras de instrumentalizar os objetivos já previstos no planejamento, seja setorial ou nacional. A questão é que essas normas se destacam dos demais do campo do Direito Econômico em virtude de seu caráter inicialmente dispositivo e de sua interpretação típica de direito público. Assim, há sentido em se defender a especialização do Direito Econômico do Planejamento, seguindo a linha argumentativa de Eros Roberto Grau e Washington Peluso Albino de Souza (SOUZA, 1980, p.08).

A legislação de pesca no Brasil inclui uma extensa e variada quantidade de normas de cunho econômico, tanto Institucionais (com a criação da Superintendência para o Desenvolvimento da Pesca - SUDEPE) como de Fomento (dispositivos de incentivo no Código de Pesca de 1967. Tais instrumentos normativos, vale ressaltar, foram previstos para a promoção de finalidades determinadas politicamente, por meio de planos gerais e setoriais. No caso específico, pretende-se analisar as normas de fomento destinadas ao desenvolvimento do setor pesqueiro, cujo sentido foi historicamente traduzido como industrialização da pesca. 


\section{DOS SUBSÍDIOS PREVISTOS NO CÓDIGO DE PESCA DE 1967 AO IDEARIO DE REESTRUTURAÇÃO PRODUTIVA}

O Decreto-lei n. 221, de 28 de fevereiro de 1967 (Código de Pesca de 1967) foi o instrumento legal que regulamentou a atividade pesqueira no Brasil desde sua entrada em vigor até a parcial revogação, por meio da Nova Lei de Pesca, de 2009 (Lei n. 11.959, de 29 de junho de 2009). Durante sua vigência, o Código sofreu muitas alterações, especialmente nas previsões denominadas como medidas de estímulo para empresas pesqueiras. Essas mudanças durante os aproximados 22 anos de sua vigência não afetaram substancialmente o consagrado modelo de gestão pesqueira via subsídios para a indústria pesqueira.

Sendo o primeiro instrumento legal a prever modalidades de fomento à produção pesqueira empresarial especificamente, via isenções fiscais, o Código de Pesca de 1967 veio a atender a demanda dos produtores em larga escala. Esses, desde o início da década de 1960, pleiteavam a extensão dos benefícios previstos à agricultura para seus negócios 12 .

Antes dessa previsão, alguns programas locais de auxílio aos pescadores foram elaborados pelo Ministério da Agricultura, entretanto, sem o caráter de generalidade como as medidas previstas pelo Código (VAZZOLER, 1975, p.288-289). Além do mais, caracterizavam-se muito mais como medidas assistenciais, comumente concretizadas por meio da Policlínica dos Pescadores ou, muito eventualmente, pela Caixa de Crédito. A partir da formação da SUDEPE, originou-se um canal de negociação específico e direto entre os produtores industriais do setor pesqueiro e o governo federal, através do qual se esperava dinamizar a indústria pesqueira. O objetivo governamental último era concretizar o Plano Nacional de Desenvolvimento da Pesca, com o fomento das indústrias vinculadas ao setor pesqueiro. A pretensão era superar o modelo artesanal através da industrialização, sob o argumento de incrementar a produção nacional bruta de pescado.

A conturbada gestão da SUDEPE nos seus primeiros anos de existência, reflexo da instabilidade institucional nacional, impediu uma atuação mais sistemática desta autarquia. Existem notícias de que, entre 1962 e 1966, a SUDEPE investiu nos projetos do Programa de Emergência cerca de Cr\$ 18.492,3 milhões (VAZZOLER, 1975, p.286). Esse programa contemplava desde a estruturação de escolas de pesca (como a Escola Tamandaré, em Pernambuco) até a importação de maquinário para reestruturação das 
empresas pesqueiras. Apesar do volume de investimentos, não houve incremento significativo no índice de capturas

\footnotetext{
${ }^{12}$ Um dos benefícios previstos era o crédito rural, estabelecido pela Lei n. 4.829 , de 05 de novembro de 1965. Por essa linha de crédito, os empréstimos contavam com juros abaixo do mercado e, por vezes, até negativos. (PINTO, 1980, p. 38).
}

de espécies marítimas. Dados da SUDEPE apontam que o total de 337.760 toneladas de pescado foram desembarcados em 1962, avançando para 351.291 toneladas em 1966 (ABDALLAH; BACHA, 1999, p. 11).

Assim, a prevista expansão dos índices de produção pesqueira não foi realizada nesse período inicial de investimentos da SUDEPE. A insuficiência dos investimentos públicos, seja na oferta de linhas de crédito ou empregados na construção pública de entrepostos pesqueiros, motivava a insatisfação dos produtores e as crises cíclicas no abastecimento do mercado. Ademais, os problemas de abastecimento não apenas de pescado, mas de toda a sorte de gêneros alimentares eram frequentes, justificando a preocupação governamental com o processo inflacionário (ABREU, 1990).

Os primeiros anos de fomento pesqueiro via SUDEPE demonstraram que a baixa produtividade do setor pesqueiro nacional era devida não somente aos escassos investimentos públicos ou privados, mas essencialmente à falta de coordenação destes. Enquanto recursos estatais eram destinados prioritariamente à construção de entrepostos e à importação de embarcações, não havia investimentos na construção de estaleiros nacionais, por exemplo. A formação de mão-de-obra especializada para a indústria pesqueira era também desatrelada da concessão de garantias aos trabalhadores. Outro aspecto nevrálgico era a falta de infraestrutura para transporte e distribuição do pescado, sendo insuficientes os frigoríficos e mesmo os caminhões disponibilizados para tal mister. Esse descompasso, identificado como falta de planejamento para o setor, comprometeu os investimentos, cujo montante, embora significativo, não foi suficiente para alavancar a produção pesqueira industrial.

A falta de estrutura básica para o incremento da produção pesqueira causava profunda insatisfação entre os produtores, os quais exigiam que o Estado suprisse tal deficiência. É curioso que os investimentos privados eram destinados à manutenção de embarcações, mas não à estruturação ou à infraestrutura do setor. Nesse panorama, os produtores defendiam que gerar infraestrutura produtiva era função estatal, a qual os governos estavam negligenciando até então. 
Por isso, a maior demanda dos produtores do setor pesqueiro era uma nova regulamentação que substituísse a vigente (Lei de Pesca de 1938), considerada ultrapassada face aos desafios do desenvolvimento da pesca nos anos 1960. Era necessária uma legislação fundamentalmente de fomento para o setor pesqueiro, de forma a considerar a pesca como importante atividade produtiva a ser estimulada e não meramente autorizada. Esse discurso, à época, era sinônimo de investimentos públicos no setor pesqueiro, para além da regulamentação. Arriscando um pouco mais, o que os empresários pleiteavam era a conformação de um Direito Econômico do Setor Pesqueiro pautado em normas de planejamento e não somente em normas regulamentares, como vinha ocorrendo até então.

A perspectiva de que a legislação de pesca vigente à época era atrasada e insuficiente para o desenvolvimento do setor surgiu pela comparação entre esta e a legislação destinada à agricultura. Enquanto o Ministério da Agricultura gerenciava programas de estímulo e investimentos no campo, a divisão de Caça e Pesca do mesmo Ministério limitava-se a controlar e a cadastrar pescadores e empresas pesqueiras. Em suma, o setor demandava um tratamento paritário com outras atividades produtivas, mediante previsão legal em um estatuto próprio de medidas de estímulo à atividade pesqueira.

Em atenção a essa demanda setorial, a proposta conjunta da SUDEPE e do Ministério da Agricultura, remetida como anteprojeto de Lei à presidência da República em 1965, previu uma série de incentivos fiscais às empresas pesqueiras. Ao lado da autorização às embarcações estrangeiras para exploração dos recursos pesqueiros nas águas territoriais brasileiras (até então limitadas em três milhas náuticas da costa, graças à prática assentada em direito internacional), a nova legislação priorizava a industrialização da atividade. Por isso, os incentivos foram previstos unicamente em benefício de pessoas jurídicas do setor (ou seus investidores), inclusive em um capítulo específico e especial do anteprojeto.

Para encerrar qualquer dúvida a respeito da consideração estatal da atividade pesqueira dentre aquelas mais importantes para a produção nacional de alimentos, o Anteprojeto previu a elevação da indústria pesqueira à categoria de indústria de base. Essa previsão, naquele contexto de fomento estatal às atividades produtivas, permitia antever uma série de subsídios públicos ao setor ${ }^{13}$. 
Esse dispositivo não foi objeto de emendas no Congresso Nacional quando da discussão do Anteprojeto e não sofreu grandes alterações pelo próprio Código de Pesca de 1967, resguardado em seu art. 18. O relevante dessa redação foi não apenas identificar a indústria pesqueira como de base, mas principalmente estabelecer o tratamento diferenciado entre produtores autônomos (armadores) e empresas pesqueiras.

Enquanto o caput do artigo anteriormente transcrito prevê a consideração especial às empresas do setor, os armadores passaram a ser equiparados a produtores rurais. A

13

Art. 17 - Para os efeitos desta lei define-se como "indústria da pesca", sendo consequentemente declarada "indústria de base", o exercício de atividades de captura, conservação, beneficiamento, transformação, ou industrialização dos seres animais ou vegetais que tenham na água o seu meio natural ou mais frequente de vida, com o objetivo de transferir esses produtos a terceiros.

Parágrafo único - As operações de captura e venda "in natura" de pescado, quando realizadas pelos armadores de pesca, são consideradas atividades agropecuárias (BRASIL, 1966, p. 10).

consequência dessa diferenciação revela-se no campo dos estímulos estatais à pesca. Uma vez que as modalidades de subsídios previstas no Código de Pesca estímulos tinham como beneficiários somente as indústrias pesqueiras, estavam imediatamente excluídos do fomento estatal os produtores individuais e as cooperativas, pelo disposto no parágrafo único.

Essa previsão comprova não somente o interesse político na industrialização da atividade pesqueira, mas também o abandono do modelo de pesca artesanal ou de pequena unidade produtiva. Revela o esforço estatal para alteração da base produtiva até então predominante no setor pesqueiro, pautado em embarcações rústicas e de pouca autonomia de navegação. Ao longo do tempo, esse desestímulo à pesca artesanal determinou no setor a migração da mão-de-obra da pesca autônoma artesanal para a pesca industrial, fenômeno apresentado por Antônio Carlos Sant'Ana Diegues como a proletarização dos pescadores (DIEGUES, , p. 149). Paralelamente, os subsídios à indústria pesqueira conformaram alterações na base produtiva e nas frotas, o que será examinado a seguir.

O foco conferido à legislação e, por consequência, à atuação das instituições públicas em prol da industrialização "induzida" do setor pesqueiro justificava, portanto, a revogação da legislação vigente pelo anteprojeto. Essas medidas de estímulo à indústria eram consideradas vitais para garantir o incremento da produção bruta de pescado, tanto para abastecer o crescente mercado interno de alimentos ${ }^{14}$, como para exportação. Nota-se o vínculo imediato propagado pelo governo entre produtividade e industrialização.

A Lei de Pesca antecedente (Decreto-lei n. 794, de 19 de outubro de 1938) passou a ser considerada pelo governo federal um empecilho ao implemento da Política Nacional 
para o Desenvolvimento da Pesca e, portanto, à sua industrialização. Tal óbice só poderia ser superado por uma nova legislação considerada moderna, coerente com as necessidades de incremento produtivo do setor:

Realmente, o Código de Pesca atual, instituído pelo Decreto-lei n. 794, de 19.10.1938, não mais atende as exigências atuais, constituindo-se, ainda, sério entrave ao desenvolvimento do setor pesqueiro nacional, que está a reclamar uma

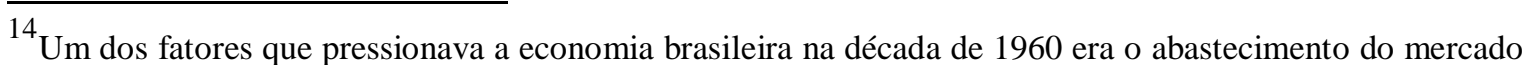
interno de alimentos. Isso porque a produção agropecuária não era suficiente para suprir a população crescente do país. Além disso, o êxodo rural, com o crescimento da população urbana agravou a crise de abastecimento. Segundo o IBGE, em 1940 a maioria da população brasileira era rural (68,76\%). Já em 1960, a situação demográfica mudou drasticamente - a população rural decaiu para $54,92 \%$, mesmo com o crescimento populacional total de $58,10 \%$. Apesar do acréscimo bruto da produção de alimentos em decorrência da mecanização, os preços dos alimentos no mercado interno auxiliavam a impulsionar a inflação no período. Se na década de 1940 a inflação média foi de $6 \%$, no início dos anos 60 o índice de inflação ultrapassou os 30\%. A alternativa adotada foi a supressão do valor real dos salários e, consequentemente, foi necessário implementar políticas para a contenção do preço dos alimentos. Para tanto, políticas de estímulo da produção agropecuária foram adotadas pelo governo federal, especialmente durante os primeiros anos do Regime Militar. Nestes termos, conferir: INSTITUTO BRASILEIRO DE GEOGRAFIA E ESTATÍSTICA, 1997.
\end{abstract}

legislação dentro da técnica moderna e que venha eliminar todas as dificuldades existentes (BRASIL, 1966, p. 141).

Nos primórdios da SUDEPE, industrializar a pesca foi a maneira prevista pelo governo federal para alcançar índices de produção suficientes para suprir a demanda interna de alimentos. Do mesmo modo como a mecanização da produção rural foi responsável pelo incremento do número bruto da oferta de produtos, a expectativa era de que a industrialização da pesca pudesse gerar resultados similares ${ }^{15}$. Mas este processo não seria simples. Enquanto a produção rural sofreu os primeiros impactos da mecanização durante as décadas de 40 a 60, o setor pesqueiro contava com pouquíssimas embarcações industriais motorizadas (de médio a grande porte) ${ }^{16}$. Por isso, a maior parte da mão-de-obra pesqueira estava concentrada na produção artesanal, como simples atividade complementar à produção agrícola de subsistência (DIEGUES, 1983, p.87). Oficialmente, a incipiente profissionalização e mecanização do setor pesqueiro brasileiro justificavam sua baixa eficiência quando comparado ao desempenho de outros setores produtivos nas décadas entre 1940 - 60 .

Adaptar a produção pesqueira aos padrões industriais passou a ser a preocupação institucional que condicionou a criação da SUDEPE, inicialmente destinada ao abastecimento do mercado interno com proteína considerada barata. A razão desse esforço 
governamental no aumento da oferta de alimentos é simples: tratava-se de gerenciar a crise inflacionária, impulsionada pelo aumento acelerado da demanda e, consequentemente, dos preços dos gêneros alimentícios. Nesse contexto, é possível compreender a urgência do governo federal em gerar e aparelhar a indústria pesqueira nacional. Disponibilizar mais alimentos significava controlar os preços e a inflação. Por isso, explorar ao máximo possível os recursos pesqueiros era necessário e justificava o montante de investimento público para promover o desenvolvimento industrial do setor.

A questão é que os pescadores na década de 1960, em sua quase totalidade eram dedicados à pesca artesanal e autônoma. $\mathrm{O}$ excedente era comercializado, a fim de obter produtos agrícolas que não conseguiam produzir. Essa produção era o que correspondia

\footnotetext{
${ }^{15}$ Segundo dados do IBGE , em 1940 existiam nas propriedades rurais brasileiras 3.380 tratores, número que atingiu 61.345 unidades em 1960. O incremento da produção rural foi geral e bastante acentuado, com crescimento de todas as culturas, notadamente a duplicação da colheita de milho e o aumento em quatro vezes da produção de arroz no intervalos entre as duas décadas. A pecuária também foi intensificada, com a duplicação do rebanho bovino. A expectativa governamental declarada era de que fosse possível estimular a produção pesqueira em níveis industriais, a fim de atingir a mesma eficiência que a produção rural. INSTITUTO BRASILEIRO DE GEOGRAFIA E ESTATÍSTICA. Censos demográficos de 1950, 1960, 1970, 1980, 1991, 2000 e 2010.

${ }^{16}$ Em 1960, de acordo com a SUDEPE, somente $2 \%$ do total das embarcações pesqueiras no Brasil eram motorizadas, totalizando 2.240 barcos. Quase a totalidade das embarcações eram movidas a vela ou a remos, pequenas embarcações com pouca autonomia e limitadas à pesca costeira. (DIEGUES, 1983, p. 145).
}

sempre a mais de metade de toda a produção nacional bruta de pescado, mesmo durante a fase de incentivos às indústrias. Muitos dos pescadores eram também pequenos proprietários rurais, o que fazia da pesca uma atividade complementar. Enquanto a produção agrícola no Brasil encontrava sua base nos latifúndios, muitos deles existentes desde tempos coloniais, a pesca apresentava como base produtiva consolidada a pequena propriedade, o que não era considerado como uma estrutura adequada pelos governos. Por esse argumento nada técnico, justificou-se o investimento estatal na formação da indústria pesqueira no Brasil.

Com as mudanças institucionais ocorridas no Brasil em 1964, verifica-se a transformação do pensamento econômico, o que veio a refletir no processo de planejamento e, por consequência, nas políticas adotadas para gestão do setor pesqueiro. Por um lado, o Plano Trienal, de autoria de Celso Furtado, orientava o governo do presidente João Goulart ao controle inflacionário via substituição de importações e controle dos preços no mercado interno. Na sequência, com a derrocada do presidente pelos militares, o Plano Trienal foi substituído pelo PAEG (Programa de Ação Econômica do Governo), capitaneado por Roberto Campos. A orientação econômica ortodoxa 
determinou a reforma tributária, com a proteção aos grandes investidores, e a reforma trabalhista, com a restrição do direito de greve. Ainda na contenção do avanço inflacionário, o setor produtivo foi ganhou nova conformação, com estímulos físcais e monetários que fizeram os produtores privilegiar as exportações em detrimento do mercado interno (BASTIAN, 2013).

Essa alteração do foco produtivo é interessante por revelar, particularmente no setor pesqueiro, a necessidade de abandonar a legislação vigente, com a previsão de estímulos destinados à indústria. Anteriormente à alteração institucional e ao PAEG, os investimentos públicos realizados pela SUDEPE priorizavam o incremento da produção nacional pesqueira para o abastecimento dos grandes centros urbanos. Com isso, pretendia-se substituir o consumo da carne bovina, de elevado preço, pela barata proteína do peixe. Assim, planejava-se atingir o equilíbrio dos preços e a liberação da carne bovina para exportação.

Antes do PAEG não era um objetivo imediato a industrialização da pesca, mas sim elaborar técnicas de conservação e adquirir aparelhagem para distribuição do pescado (VAZZOLER, 1975, p. 287). Em outros termos, a base produtiva da pesca centrada em pequenas unidades não era necessariamente um problema, mas sim a ausência de técnicas para conservação, manipulação e distribuição dos produtos pesqueiros. Portanto, a política de subsídios às empresas realmente não era prioridade, sendo o foco das medidas setoriais à pesca projetos locais, sem uma proposta de industrialização do setor pesqueiro.

Sob a égide do PAEG, entretanto, os planos para o desenvolvimento da pesca foram alterados. Se antes a base produtiva não era o grande problema para o incremento da produção pesqueira, esta passou a ser considerada o principal entrave para o setor. Por isso, medidas de estímulo às empresas pesqueiras começaram a ser elaboradas pela SUDEPE. O objetivo da produção da pesca, assim como de toda a atividade nacional era, prioritariamente, equilibrar a balança comercial brasileira pela exportação, de forma a conter o avanço inflacionário. Sob tal perspectiva ortodoxa é que se deve compreender a origem dos subsídios previstos no Código de Pesca de 1967.

Assim, o debate sobre a concessão de subsídios às empresas do setor pesqueiro surgiu desde o início dos anos 1960, mas se tornou corrente mediante a mudança institucional vivenciada com a instauração do regime militar. As reivindicações dos empresários foram divulgadas pela própria imprensa, especialmente pelos jornais de circulação nacional, como o Correio da Manhã. E mais, não apenas os empresários do 
setor estavam insatisfeitos, mas essencialmente os potenciais investidores, sobretudo estrangeiros. Um exemplo foi o proprietário da Indústria Naval do Ceará (INACE), o bancário Gil Bezerra. Seu propósito era construir um estaleiro nacional para grandes embarcações; entretanto, a ausência de estímulos estatais tornava o projeto inviável. Somente com a previsão pelo Código de Pesca de 1967 de medidas de incentivo é que o projeto da INACE pode ser realizado, com a fundação da empresa em 1969 (INACE, 2015).

Em atenção à demanda dos empresários do setor e visando ao incremento das exportações, a nova direção da SUDEPE assumiu a tarefa de organizar uma legislação de pesca considerada moderna, com previsão de estímulos estatais à industrialização do setor. Foi sob tal perspectiva que o Anteprojeto de lei elaborado pela SUDEPE e encaminhado ao Presidente Castelo Branco em 1965 estabeleceu uma série de benefícios fiscais às empresas pesqueiras.

A primeira medida de estímulo prevista foi a concessão, pelo prazo de cinco anos, de isenção dos impostos de importação e de consumo, bem como de todas as taxas aduaneiras e federais para a importação de embarcações e equipamentos pesqueiros por pessoas jurídicas. Para tanto, era preciso que a empresa contasse com projetos aprovados pela SUDEPE. O mesmo benefício foi previsto para empresas que importassem equipamentos destinados ao processamento, industrialização e comercialização de pescados, nos termos do dos artigos 74 e 75 do anteprojeto.

Essa previsão sofreu emenda na Comissão de Projetos do Executivo (CPE) do Senado Federal, ganhando nova redação que estabelecia o prazo de isenção até 1972, bem como a alteração das isenções, que recairiam sobre o imposto de importação (II) e o imposto sobre produtos industrializados (IPI). O motivo dessa última emenda foi simplesmente adequar o Anteprojeto à reforma tributária já promovida, que substituiu o imposto de consumo pelo IPI.

As empresas pesqueiras também se tornariam isentas do mesmo imposto de consumo (substituído pelo IPI) sobre os petrechos de pesca, bem como sobre os produtos pesqueiros industrializados ou não, tanto destinados ao mercado interno como para exportação. A emenda sofrida pelo dispositivo na CPE já mencionada limitou ao prazo de cinco anos as isenções previstas (BRASIL, 1966, p. 78).

Outra medida de estímulo foi prevista pelo mesmo Anteprojeto foi a isenção do Imposto de Renda (IR) incidente sobre o lucro real tributável obtido por pessoas jurídicas 
do ramo pesqueiro, desde que sediadas no país e com planos aprovados pela SUDEPE. Essa isenção foi estabelecida pelo prazo de 05 (cinco) exercícios financeiros consecutivos, a fim de possibilitar o reinvestimento dos valores do tributo para modernização das próprias empresas.

Por fim, o Anteprojeto previu nos artigos 80 e 83 isenção do IR para pessoas jurídicas e físicas até o exercício financeiro de 1971 sobre o lucro real tributável, para que este montante fosse investido na subscrição de capital de empresas pesqueiras com projetos aprovados na SUDEPE. A emenda proposta pela Comissão de Finanças do Senado (CF) incluiu a isenção não somente sobre o lucro tributável, mas sobre o total da renda bruta.

Essa ampliação das isenções previstas, especialmente referentes ao IR, teria causado desagrado ao presidente Castelo Branco. Por isso, nas razões de veto transcritas na Mensagem n. 105, de 18 de janeiro de 1967 que a alteração da política fiscal proposta fez com que o Projeto de Lei deixasse "de ser do interesse nacional". Segundo as razões presidenciais, a extensão do art. 77, que pela emenda parlamentar englobou também o IPI comprometeria o orçamento da União, sendo esta sua maior receita à época ${ }^{17}$.

Com o veto em janeiro de 1967 do então Estatuto da Pesca, após a tramitação em regime de urgência do Projeto de Lei, o Poder Executivo continuava com o problema de adaptar a legislação vigente às necessidades e demandas do setor. Por isso, com poucas alterações sobre o Anteprojeto encaminhado anteriormente para o Legislativo, o próprio presidente da República, em acordo com seus Ministros da Fazenda e da Agricultura, decretou o Código de Pesca, em 28 de fevereiro do mesmo ano.

A diferença entre o texto do Decreto-Lei 221/1967 e a proposta original do

$\overline{17}$ BRASIL. Congresso Nacional. Mensagem Presidencial n. 105, p. 28.

Anteprojeto era a fixação expressa do limite dos benefícios, válidos até o ano de 1972. Além disso, o incentivo via isenção do IR para pessoas físicas e jurídicas investidoras do setor pesqueiro foi limitado a $25 \%$ sobre o imposto devido, a fim de estimular inversões. No mais, o texto manteve praticamente as previsões do anteprojeto, sendo, portanto, adequado aos interesses do governo Castelo Branco.

As medidas de estímulo previstas pelo Código de Pesca de 1967 foram prorrogadas por diversas ocasiões. As previsões de isenção do II e do IPI foram válidas até 1982. Já a isenção sobre o IR foi estendida, sucessivas vezes, até 1986. Vale ter em 
consideração que essas medidas comprometeram a gestão pesqueira nacional com um modelo de subsídios que, segundo a classificação já apresentada por William E. Schrank, beneficia o setor subsidiado de maneira indireta (SCHRANK, 2003, p. 14).

Considerando-se as medidas de estímulo à pesca, bem como a autorização de exploração pesqueira por empresas e embarcações estrangeiras, ficou explícita a concepção estatal da pesca como atividade produtiva de interesse nacional. O modelo de gestão pesqueira adotado via subsídios era inspirado por essa concepção; com esse panorama, compreende-se o silêncio institucional a respeito da possível depleção dos estoques e mesmo extinção de espécies. Ademais, o estágio da ciência pesqueira internacional considerava as áreas sem comprovação de esgotamento de recursos como íntegras, devendo ser exploradas em benefício das demandas alimentares mundiais.

Identificado o modelo de gestão pesqueira utilizado no Brasil, é possível, a partir dessa informação, analisar os efeitos dessas políticas. Mais ainda, prossegue-se na correlação entre planejamento e gestão pesqueira, condicionantes do conteúdo das normas de Direito Econômico do Setor Pesqueiro.

\section{CONCLUSÃO}

A política de fomento à produção pesqueira no Brasil foi prevista, essencialmente, pelo Código de Pesca de 1967. Os instrumentos de tal política foram subsídios, sobretudo na forma de isenções fiscais. Tais subsídios tiveram como destinatários unicamente empresários do setor pesqueiro, estimulando a produção pesqueira industrial em detrimento da modalidade artesanal.

Tais afirmações ganham sentido quando são analisados os dispositivos do Código de Pesca de 1967 que se constituem como normas de direito econômico. Para tanto, é preciso admitir a existência de um campo normativo destinado a prever as políticas econômicas a

serem adotadas, o qual transcende a ideia de unidade codificada e perpassa por toda a ordem jurídica. Nesse sentido, podem ser encontradas normas de direito econômico nos mais diversos diplomas legais, como é o caso dos dispositivos de fomento previstos no Código de Pesca de 1967. 
Por tal perspectiva, é possível admitir a existência de um direito econômico do setor pesqueiro que, no caso específico do Brasil, foi utilizado como instrumento para a promoção da restruturação produtiva da pesca nacional. Tal fenômeno se verifica em dois níveis. O primeiro deles é a própria definição da pesca entre as modalidades artesanal e industrial. No segundo nível, a política produtiva tratou de suplantar a pesca artesanal pelo modelo industrial, destinando a este a totalidade dos subsídios previstos. Desta forma, tem-se, como conclusão que o direito econômico do setor pesqueiro serviu, e muito, como fundamento jurídico para a execução de uma política de restruturação produtiva setorial, indiferente às variáveis ambientais e sociais envolvidas.

\section{REFERÊNCIAS BIBLIOGRÁFICAS}

ABDALLAH P. R.; BACHA C. J. C. Evolução da atividade pesqueira no Brasil: 19601994.

Teoria e evidência econômica, vol. 7, n. 13, p. 9-24, 1999.

ABREU, Marcelo Paiva de (org.). A ordem do progresso: cem anos de política econômica

republicana (1889-1989). Rio de Janeiro: Elsevier, 1990.

ARISTÓTELES. Metafísica. Tradução de Leonel Vallandro. Porto Alegre: Globo, 1969.

BASTIAN, Eduardo F. O PAEG e o plano trienal: uma análise comparativa de suas políticas de estabilização de curto prazo. Estudos Econômicos, vol. 43, n.1, p. 139-166, jan.-mar. 2013.

BRASIL. Câmara dos Deputados. Mensagem n. 105. Projeto de Lei 3906/1966. Disponível em: <http://www.camara.gov.br/proposicoesWeb/; PL+3906/1966>. Acesso em: 05 jan. 2015.

-----. Projeto de Lei 3906/1966. Dispõe sobre a proteção e estímulo da pesca e dá outras providências. Disponível em:

<http://www.camara.gov.br/proposicoesWeb/prop_ =PL+3906/1966>. Acesso em: 05 jan. 2015.

CAL, Arianne Brito Rodrigues. As agências reguladoras no Direito brasileiro. Rio de Janeiro: Renovar, 2013.

CARVALHOSA, Modesto Souza Barros. Considerações sobre o Direito Econômico. São Paulo: Unidas, 1971.

CHENOT, Bernard et al. Dictionnaire des sciences économiques. Org. ROMEUF, Jean; 
PASQUALAGGI, Gilles. Paris: Presses universitaires de France, 1956. 630p. v.1.

COMPARATO, Fábio. O indispensável direito econômico. Revista dos Tribunais, n. $353, \mathrm{p}$.

14-26, 1965.

DIEGUES, Antônio Carlos Sant'Ana. Pescadores, camponeses e trabalhadores do mar. São Paulo: Ática, 1983.

GRAU, Eros Roberto. A ordem econômica na Constituição de 1988. 11. ed. São Paulo: Malheiros, 2007.

INACE. Histórico da empresa. Disponível em:

<http://www.inace.com.br/old/novo/?pagina=historico>. Acesso em: 14 fev. 2015.

INSTITUTO BRASILEIRO DE GEOGRAFIA E ESTATÍSTICA. Anuário Estatístico do Brasil. Rio de Janeiro: FIBGE, 1966-1986.

-----. Censos demográficos de 1950, 1960, 1970, 1980, 1991, 2000 e 2010. Disponível em:

<http://www.sidra.ibge.gov. br>. Acesso em: 20 de janeiro de 2015.

NEUMANN, Franz. Estado democrático e Estado autoritário. Rio de Janeiro: Zahar, 1969.

PINTO, L. C. G. Notas sobre a política e crédito rural. Campinas: UNICAMP, 1980.

PRADO JÚNIOR, Caio. História econômica do Brasil. 10. ed. São Paulo: Brasiliense, 1967.

RODRIGUEZ, Octávio. Teoria do subdesenvolvimento da CEPAL. Rio de Janeiro:

Forense-Universitária, 1981.

SCHRANK, William E. Introducing fisheries subsidies. Roma: FAO, 2003.

SILVA, Floriano Corrêa Vaz da. A intervenção do Estado no domínio econômico através dos órgãos da administração indireta. Revista de Informação Legislativa, vol. 11, n. 44, p. 31-46, out-dez. 1974.

SOUTO, Marcos Juruena Villela. Aspectos Jurídicos do Planejamento econômico.

2.ed.rev.amp. Rio de Janeiro: Lumen Iuris, 2000.

SOUZA, Washington Peluso Albino de. Direito Econômico. São Paulo: Saraiva, 1980.

VAZZOLER, Gelso. A pesca marítima no Brasil. In: ROTHSCHILD, Brian J (org.). A pesca:

seus recursos e interesses nacionais. São Paulo: IBRASA, 1975. 
VENANCIO FILHO, Alberto. A intervenção do Estado no domínio econômico. Rio de Janeiro: Fundação Getúlio Vargas, 1968.

VIANNA, Oliveira. Problemas de Política Objetiva. 2.ed. São Paulo: Companhia Nacional, 1947. 